\title{
RFID Based Manufacturing Process of Cloud MES
}

\author{
Chuang Wang ${ }^{1}$, Xu'nan Chen ${ }^{1, *}$, Abdel-Hamid Ali Soliman ${ }^{2}$ and Zhixiang Zhu ${ }^{1}$ \\ 1 Institute of Internet of Things and IT based Industrialization, Xi'an University of Posts \& \\ Telecommunications, Xi'an 710061, China; wangchuang@xupt.edu.cn (C.W.); zhuzhix@xupt.edu.cn (Z.Z.) \\ 2 School of Creative Arts \& Engineering, Staffordshire University, S231, Mellor Building, College Road, \\ Stoke-on-Trent ST4 2DE, UK; a.soliman@staffs.ac.uk \\ * Correspondence: 1703210106@stu.xupt.edu.cn; Tel.: +86-29-8538-3425
}

Received: 6 September 2018; Accepted: 24 October 2018; Published: 30 October 2018

\begin{abstract}
RFID (radio frequency identification) is widely used in the manufacturing processes of enterprises. At the same time, with the advent of the Industry 4.0 era, Manufacturing Execution System (MES) systems began to evolve into cloud MES systems. In this paper, a RFID-based manufacturing process for cloud MES is proposed and a framework manufacturing process fora cloud MES system centered on machine tools is constructed. The process division of the manufacturing process, RFID configuration and cloud processing are analyzed, and other key technologies involved in implementing the framework are briefly discussed. Finally, the effectiveness of a RFID-based manufacturing process of cloud MES is verified by two different types of case analysis namely photovoltaic slice production and garment outsourcing processing.
\end{abstract}

Keywords: RFID; cloud MES; real-time data acquisition; tracking configuration; intelligent manufacturing

\section{Introduction}

In the midst of globalization and ever-increasing market competition, product quality and production efficiency have always been both a bottleneck and the ultimate goal of manufacturing enterprises. Consequently, most manufacturing companies began to introduce the Manufacturing Execution System (MES), which is used in the manufacturing process. As early as the 1990s, the Advanced Manufacturing Research (AMR) Corporation of the United States officially proposed the concept of the MES system, and built a three-layer structure enterprise integration model, which pointed out the hierarchical position of MES [1] for the first time, since this system had been established in 1992. The Manufacturing Execution Systems Association (MESA) released the official definition of the MES system in 1997, andit contained an MES integration model which included 11 functions [2]. This traditional MES system is limited to tracking and documenting the transformation of specific information into finished goods, such as individual, machine, raw materials, method and the surrounding environment of a single production workshop (as proposed in the literature [3]: The MES system for agile manufacturing, the human-centered MES system in the networked manufacturing environment proposed by the literature [4]). Presently, following over more than 20 years of industrial development in a rapidly changing info-technology, such as cloud computing, big data and the Internet of Things (IoT), and with deep integration of next-generation information technology and industrialization, industrial manufacturing's new age, Industry 4.0 [5], is just around the corner. To extend the lifespan of businesses, traditional manufacturing enterprises are fully engaged in transformation and upgrading. In the last two years, from using traditional MES systems to custom improvements of MES systems in different enterprises, manufacturing companies in the production process have begun to evolve into using the cloud MES system with cloud manufacturing characteristics. Wang et al. combined the characteristics of cloud manufacturing, proposed a machine 
tool manufacturing MES for cloud manufacturing, and studied the part-case retrieval method, by managing manufacturing resources and allocation in the cloud manufacturing environment [6]; Helo et al. made a proposal for the core architecture of a cloud-based MES solution to meet the needs and challenges of the management of distributed manufacturing in a multi-company supply chain [7]; Zhang et al. took an industrial park with a high industrial concentration as the management objective, analyzed and discussed the construction of a cloud MES from the aspect of system design, application, operation and maintenance [8]. The future of the MES system will continue to be refined with cloud collaboration and intelligent development [9]. With the emergence of the cloud MES, the functional characteristics of the MES system have also undergone transformation. The most prominent transformation features are remote monitoring and real-time visualization. The basis for achieving these transformations and refining management objectives is based on the RFID manufacturing process's real-time tracking. RFID technology has been widely used in the manufacturing process of enterprises and has been further studied (such as in Reference [10], which involved the design of a remote monitoring system based on RFID for the internal production management of the enterprise; literature [11] studied the key technologies involved in the manufacturing execution system for a workshop-level service based on RFID; literature [12] proposed an RFID-based intelligent decision support system architecture for the production monitoring and scheduling of distributed production environments). This paper combines the cloud MES system with RFID technology to further study real-time tracking and monitoring in the manufacturing process.

\section{The General Framework of the RFID Based Manufacturing Process of Cloud MES}

In industrial production, a cloud MES system introduces cloud platform storage and big data processing technology on the basis of an MES. It is a core part of each enterprise to achieve production synergy, and it is also the key part to promote industrial production being refined, cloud-based, coordinated and intelligent. Combined with the hierarchical position of MES in the enterprise integration model and the introduction of RFID technology, this paper proposes a framework of a manufacturing process of cloud MES system centered on machine tools, as Figure 1 shows.

As shown in Figure 1, the framework of a manufacturing process via ac loud MES system centered on the processing machine tool and reflects the real-time interconnection and cloudization of the device. The overall structure mainly includes the equipment control layer, the IoT (Internet of Things) layer, the cloud MES layer and the user layer.

(1) Equipment control layer: The equipment in this layer is mainly based on the processing machine tool (or enterprise workshop), and the machine tool (or enterprise workshop) under the cloud MES system being virtualized and abstracted as a node, and as a basic manufacturing unit. Each manufacturing unit needs to be configured with RFID to match the corresponding RFID tags, providing hardware support for real-time tracking and monitoring functions in the cloud MES system.

(2) IoT layer: This layer mainly realizes the interconnection of devices between manufacturing units composed of various processing machine tools (or enterprise workshops). The main hardware devices include sensors, industrial Ethernet, fieldbus, switches and wireless network systems.

(3) Cloud MES layer: This layer integrates cloud storage, big data technology and an MES system, and is responsible for processing and feeding back the data indexes of the underlying devices uploaded through the IoT layer to realize the cloud-based, virtualized and intelligent management of the manufacturing process by the MES system. It mainly includes a cloud database, a cloud server and a big data processing system module. The cloud database is the integration of the MES database with other databases (such as ERP: Enterprise Resource Planning, SCM: Supply Chain Management, etc.). The cloud server is mainly laid on the public cloud, provided by third-party cloud providers (such as Amazon's AWS, Microsoft's Azure, and the domestic Alibaba Cloud, etc.), The big data processing system module is developed for the specific manufacturing process or as directed by a third-party vendor. 
(4) User layer: This layer mainly realizes the real-time dynamic display for the tracking and monitoring of the manufacturing process by the cloud MES layer. Under any circumstances, the user can keep track of the real-time dynamic of current manufacturing processes by using various methods (such as a web browser, application software client, AR (Augmented Reality), VR (Virtual Reality) intelligent display device, etc.).

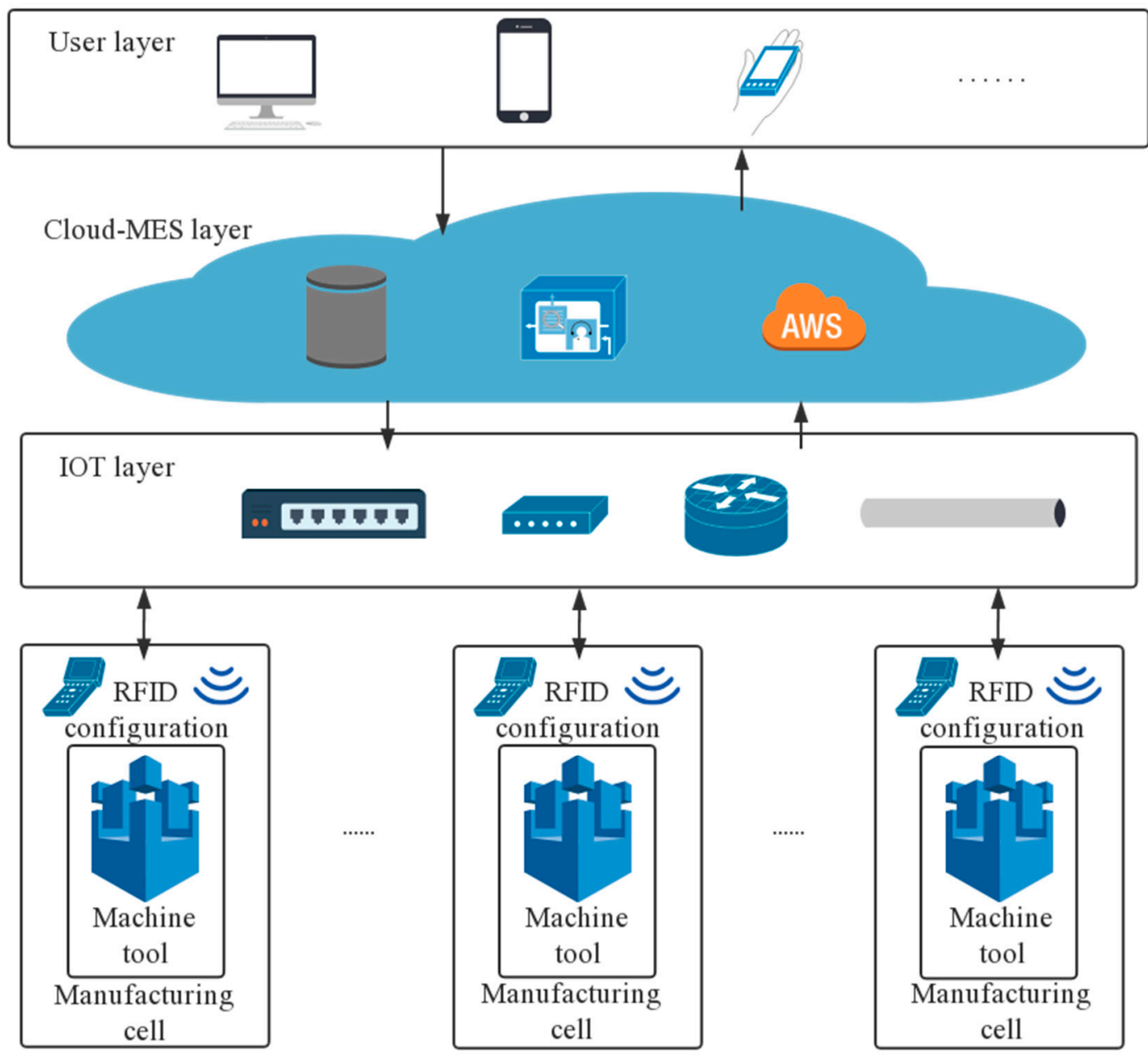

Equipment control layer

Figure 1. The framework of manufacturing process of cloud MES system diagram centered on machine tools.

\section{RFID Tracking Configuration and Cloud Processing for Manufacturing Process}

From the above-mentioned framework of the manufacturing process, the Cloud MES system is the core hub of information interaction in the framework. Real-time tracking and monitoring of the manufacturing process play a critical role in the cloud MES system module function. In order to realize real-time tracking, monitoring and refined management, the cloud MES layer needs to not only provide visual monitoring through video and/or image acquisition, but also real-time acquisition of tracking data from the bottom layer about each machine tool and each part. To respond to needs, introducing RFID technology to track and collect real-time data on machine tools and parts is necessary. In real-time tracking and acquisition, RFID technology can be divided into two parts: process division of production process and RFID tracking configuration based on process division [13,14]. 


\subsection{Process Division of the Production Process}

It has become the norm for product manufacturers to outsource manufacture, the processing of their components, to professional manufacturing service providers [15,16]. In order to reflect the synergistic trend of the cloud MES system, this section describes the case where a core enterprise outsources the required parts to assist the enterprise in production and processing. The processing relationship between a core enterprise and other outsourcing companies is shown in Figure 2.

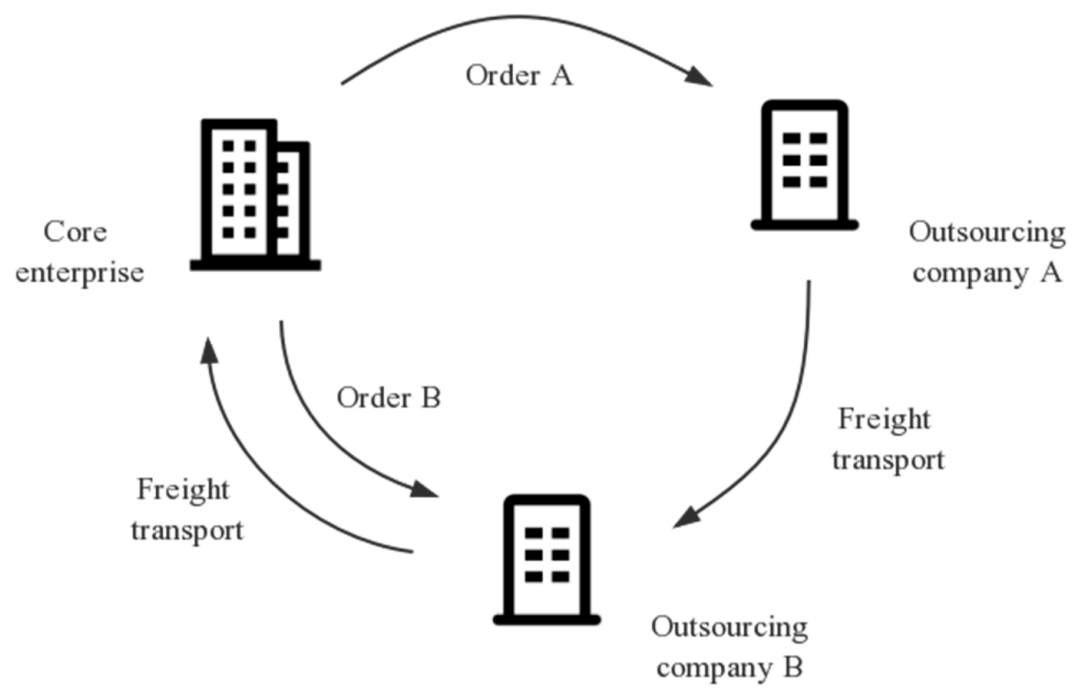

Figure 2. Processing relation diagram for external parts.

As shown in Figure 2, a core enterprise assigns parts processing orders to two outsourcing companies A and B. Among them, the outsourcing company A is responsible for completing the rough processing orders and transferring the processed parts to outsourcing company B. Outsourcing company $\mathrm{B}$ is responsible for completing the fine processing orders and transporting the processed parts to the core enterprise.

The process division of the parts production and processing process for the outsourcing companies $\mathrm{A}$ and $\mathrm{B}$ is shown in Figure 3.

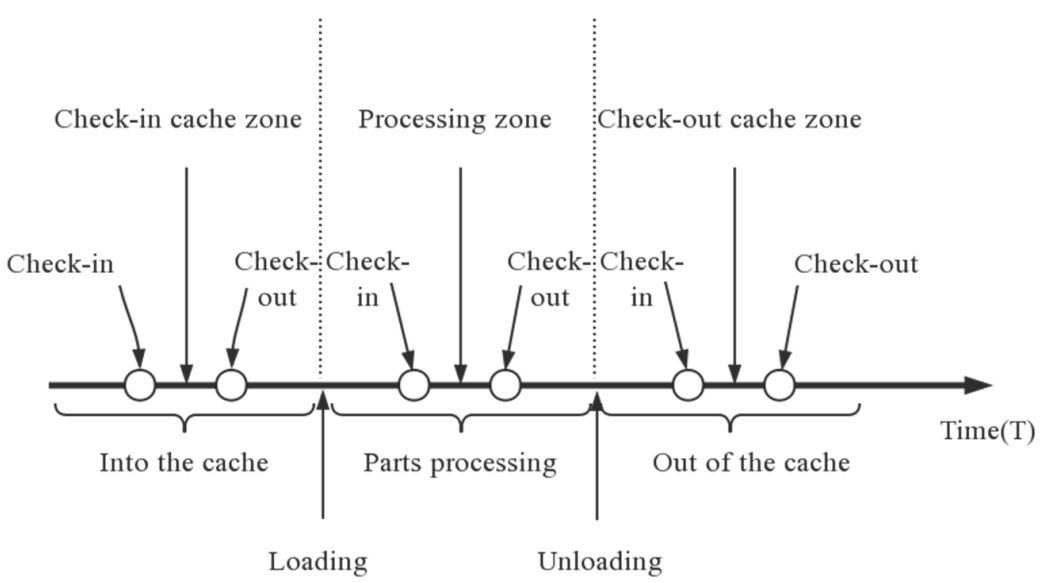

Figure 3. Outsourcing company A, B production process sequence diagram.

As shown in Figure 3, in chronological order, the production process steps of the outsourcing companies A and B can be divided into three parts: Into the cache, part processing and out of the cache. Each part is subdivided into three by adding two nodes. A small part, such as inserting two nodes into the cache part, subdivided into entering the cache, in the cache area and leaving the cache, the other 
two parts and so on, the added six nodes will be used as tracking and monitoring nodes for RFID tracking in the next step configuration.

The process division of the parts transportation system for the outsourcing enterprises A and B is shown in Figure 4.

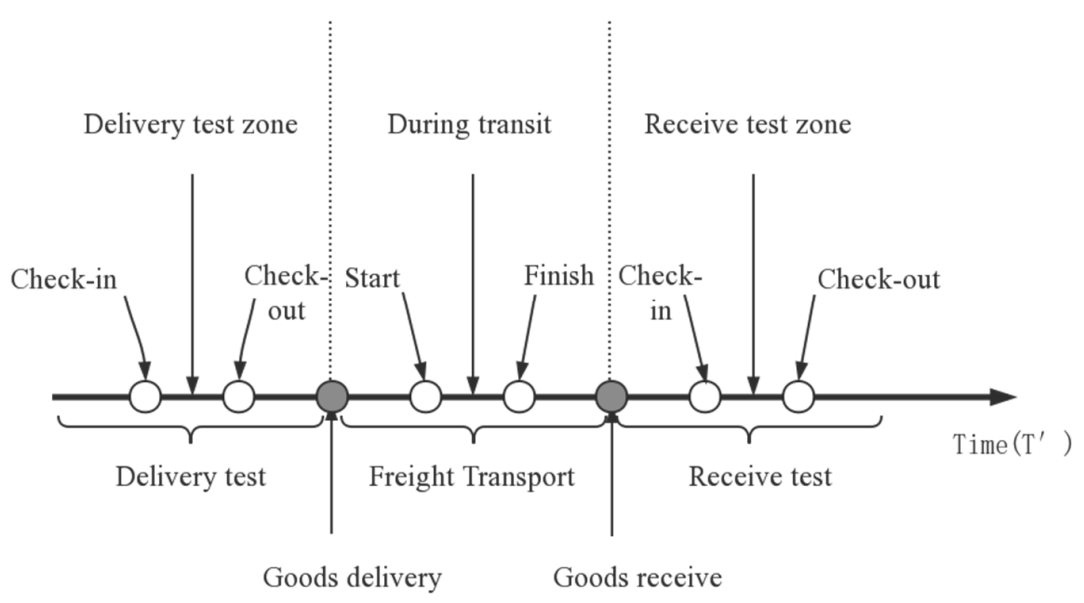

Figure 4. Outsourcing company A, B entering or leaving the plant transportation process sequence diagram.

As shown in Figure 4, in the order of time, by adding two notes, the transportation process of the outbound factories of the outsourcing companies A and B is divided into three parts: Delivery test, freight transport and receive test, and each part (as shown in Figure 4, the area surrounded by any brace is part of it) is added two more. The node is subdivided into start delivery test, the delivery test zone and finish delivery test. The other two parts are deduced by analogy. All the added eight nodes will be used as the tracking monitoring nodes in the next step perform RFID tracking configuration.

\subsection{RFID Tracking Configuration Based on Process Division}

In this part, the RFID monitoring configuration is carried out through the tracking and monitoring nodes obtained by the above-mentioned production and processing processes and the transportation process of the inbound and outbound transportation processes. The RFID tracking configuration model based on the production and processing operations is shown in Figure 5.

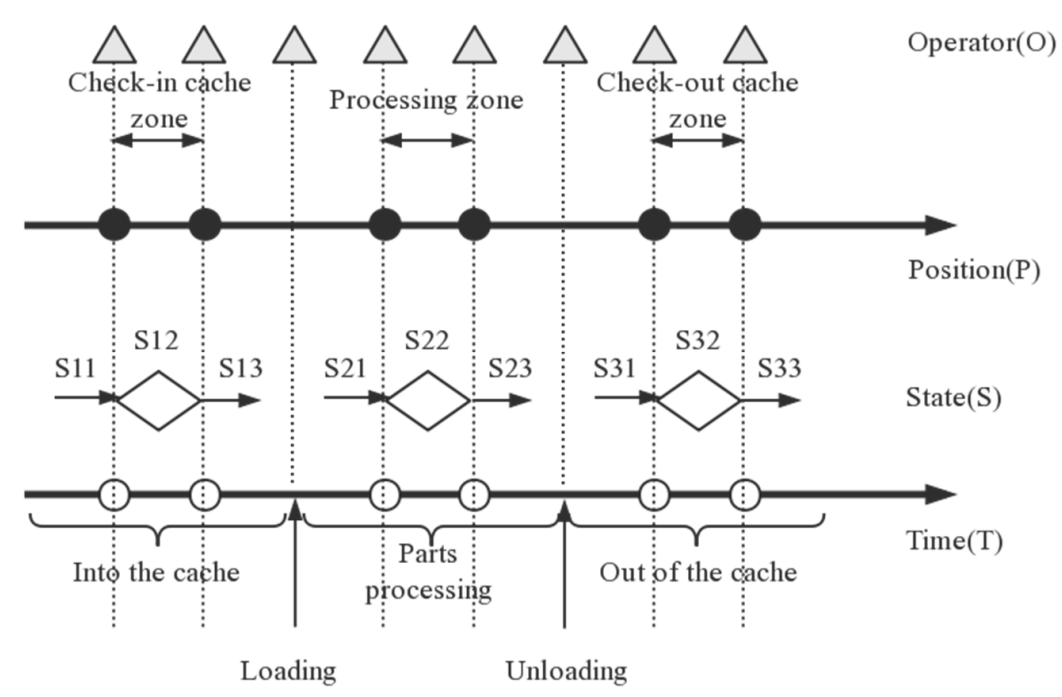

Figure 5. RFID (Radio Frequency Identification Devices) tracking configuration model based on production process. 
As shown in Figure 5, the model is based on the time axis (T). The position node in the positioning axis $(\mathrm{P})$ corresponds to the tracking monitoring node in the time axis $(\mathrm{T})$. Between the time axis $(\mathrm{T})$ and the positioning axis $(\mathrm{P})$ is the state information $(\mathrm{S})$, and outside the positioning axis $(\mathrm{P})$ is the operator information $(\mathrm{O})$. The RFID configuration for the production process is mainly centered on the machine tool, and the corresponding RFID reader is arranged at the fixed position of the machine tool. The position of the RFID reader is determined, and the tracking monitoring is added in the timing chart of the production process. Corresponding to the node, the RFID tag is attached to the part, so that during the movement of the part on the processing machine, the RFID tag attached to the part passes through the RFID read/write area of the fixed position of the processing machine tool, and real-time tracking and acquisition of the current processing status of the part can be realized. Through the RFID tracking configuration model of the production process, the tracking data of the real-time data such as the machining state of the part, the positioning of the machine tool, the operator information and the machining time can be finally realized.

The RFID tracking configuration model based on the transportation process of the inbound and outbound plants is shown in the following figure (Figure 6).

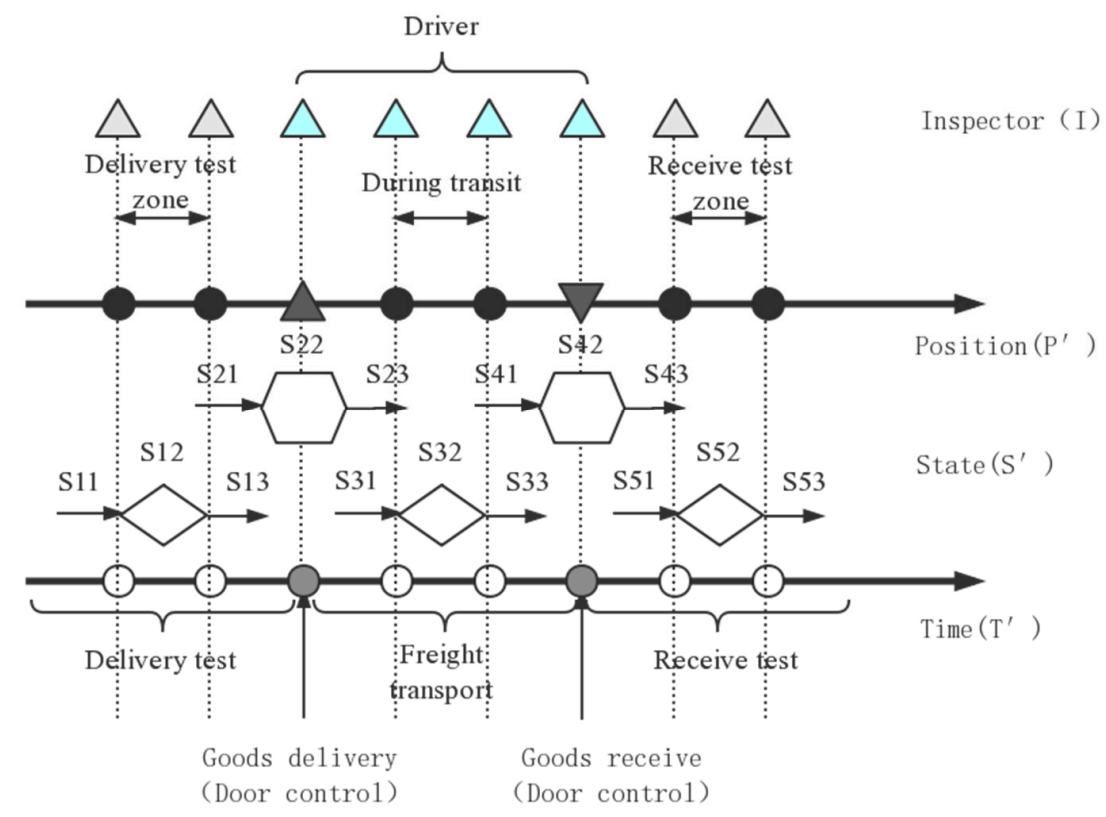

Figure 6. RFID tracking configuration model based on the transportation process of the inbound and outbound plants.

As shown in Figure 6, the model is also based on the time axis $\left(\mathrm{T}^{\prime}\right)$. The position node in the positioning axis $\left(\mathrm{P}^{\prime}\right)$ corresponds to the tracking monitoring node in the time axis $\left(\mathrm{T}^{\prime}\right)$. Between the time axis $\left(\mathrm{T}^{\prime}\right)$ and the positioning axis $\left(\mathrm{P}^{\prime}\right)$ is the state information $\left(\mathrm{S}^{\prime}\right)$, and the outside of the positioning axis $\left(\mathrm{P}^{\prime}\right)$ is the inspector and driver information (I). There are two main types of RFID configurations for the transportation process of the inbound and outbound factories. One is to configure the corresponding RFID readers at the fixed position of the timing diagram of the transportation process. Corresponding to the six tracking and monitoring nodes, the RFID tag is attached to the part. During the movement of the part on the monitoring device, the RFID tag attached to the part passes through the RFID reading and writing area at the fixed position of the monitoring device, and real-time tracking and acquisition of the current processing status of the part can be realized. The other type of RFID configuration is to configure the corresponding RFID reader at the entrance and exit of the factory, and the driver presents the access card (RFID tag) to realize the real-time tracking and collection of the current state of the cargo. Through the RFID tracking configuration model of the transportation process of the factory, the real-time data, such as the current state of the component, the positioning of the monitoring device, 
the information of the monitor, the driver, and the transportation time of the inbound and outbound plants can be finally obtained.

\subsection{Cloud MES Processing Based on RFID Configuration}

Before the production process, the cloud MES system first sends the production index generation instructions to the parts with the RFID label according to the established production plan, and realizes the production process of the parts. In the production process, on the basis of completing the corresponding RFID configuration, the process flow of each part is formed by the connection process, and the change of each process state is regarded as an event, and the process flow monitoring is formed by the event drive [17].

In terms of data processing, on the one hand, the RFID reader reads and collects the RFID data in the process flow for preprocessing. The cloud MES system automatically discriminates redundant data according to predetermined rules and performs data culling, and finally retains valid RFID data and uploads it to the cloud database. On the other hand, the collected RFID data are processed in depth. The cloud server imports valid RFID data from the database for data fusion, obtains actual production parameters, automatically generates key variables through big data analysis algorithm and machine learning modeling, forms a corresponding production parameter curve model, and calculates RFID data through streaming calculation. Real-time analysis, high-quality calculation results, real-time multi-dimensional analysis of hundreds of billions of data, and ultimately improve the quality of parts.

\section{Other Key Technologies}

In order to realize the above RFID based manufacturing process of cloud MES, RFID tracking configuration is the most basic key technology, and other key technologies involved mainly network automation configuration and cloud MES layer monitoring management, which will be briefly described below.

\subsection{Network Automation Configuration}

Different processing machine tools (or enterprise workshops) can form a community-mode sensory interconnection network through self-organization [18], and automatically configure the sensor network under the community mode, which is the basis for cloud MES to realize cloud management of the production process. The sensor interconnection network is mainly a wireless sensor network composed of multiple types of sensor modes, network routers and wireless gateways between processing machines (or enterprise workshops), wherein terminal equipment nodes of each processing machine tool are connected with matching sensor nodes, according to the tracking process the sensor is configured, and the sensor data is uploaded to the database of the cloud MES platform through the routing node and the gateway node for further data processing. In turn, it can realize efficient and reliable collection, transmission and storage processing of various machine tools and productions process information and support the optimal operation of cloud MES.

\subsection{Cloud MES Monitoring Management}

Monitoring and management refers to comparing and verifying the real-time data generated during the production process of the collected products with the ideal data, realizing the real-time visual management of the production process of the product, and finally achieving the intended production goal. Enterprises with external cooperation relationship can extract real-time tracking data from different times and spaces and different regions through cloud MES layer, and integrate with big data processing modules through the cloud MES system monitoring management module to generate a visual analysis report, and finally in mobile phones, displayed on computers, VR, AR and other equipment. In this way, the production process can be highly restored, and the production dynamics of each assembly line can be displayed. Meanwhile, an abnormal situation can provide an warning 
early, and process monitoring and quality control can be further strengthened to improve production efficiency and product quality.

\section{Case Analysis}

\subsection{Photovoltaic Slicing Production Case}

The following is a case of a new energy enterprise, producing and processing photovoltaic chips. Taking the monocrystalline silicon slice produced by the company as an example, the production process can be divided into semi-finished products, multi-process processing and finished product storage. The main processes involved in the processing include cutting, slicing, inserting and cleaning. The RFID configuration based on the process division mentioned in the previous section is shown in Figure 7. In data processing, the RFID reader collects thousands of production parameters that affect the yield of the slice and uploads them to the cloud database. The cloud server automatically analyzes 60 key variables most relevant to the yield rate in the production process through big data processing, builds the production parameter curve model for the enterprise, and analyzes and processes these variables in real time. In the end, the yield of photovoltaic chips is improved, saving millions of dollars in production costs.

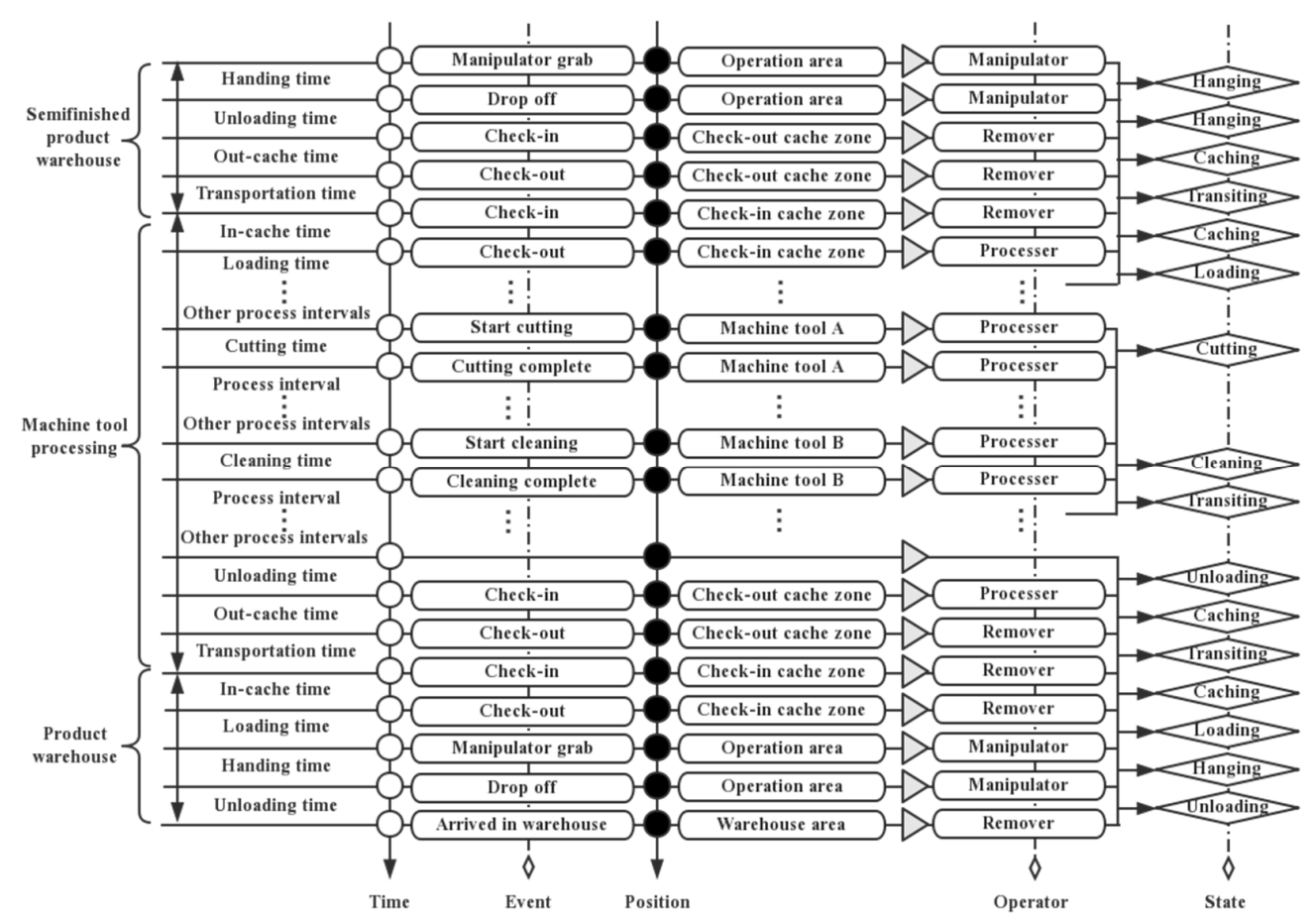

Figure 7. Process flow monitoring diagram based on RFID configuration for producing single crystal silicon chips.

\subsection{Clothing Outsourcing Processing Case}

The following is a case of a tailor-made shirt of a suit brand enterprise. The enterprise provides clothing design and order requirements, and the two garment processing factories undertake the outsourcing of processing tasks. The enterprise uses cloud MES services provided by third parties at the same time as the two factories. The cloud MES system is initialized according to the enterprise's order requirements, and the manufacturing resources of the two processing plants (such as machine tools, RFID equipment, etc.) are integrated to form a virtual joint factory (as shown in Figure 8), which is automatically generated in the cloud of the two processing plants according to the order data. According to the requirements of the cloud MES system, the garment processing factory (M) is responsible for the cutting, sewing and other pre-processing of the shirt, and transports 
the semi-finished products to the garment processing factory $(\mathrm{N})$. Garment processing factory $\mathrm{N}$ is responsible for the fine processing of clothing decoration and ironing. According to the RFID data collected by the garment processing process, the cloud MES system performs data mining through big data processing, updates the schedule in a timely manner and adjusts the production plan. In terms of logistics and transportation, according to the RFID data collected during the transfer process, the cloud MES system provides real-time monitoring of production equipment, transportation location, quality inspection personnel, and other key information for the enterprise and the two factories through real-time tracking and monitoring and mobile push; using mobile devices, such as mobile phones, to view them at any time. The formed process flow monitoring based on the RFID configuration is shown in Figure 9.

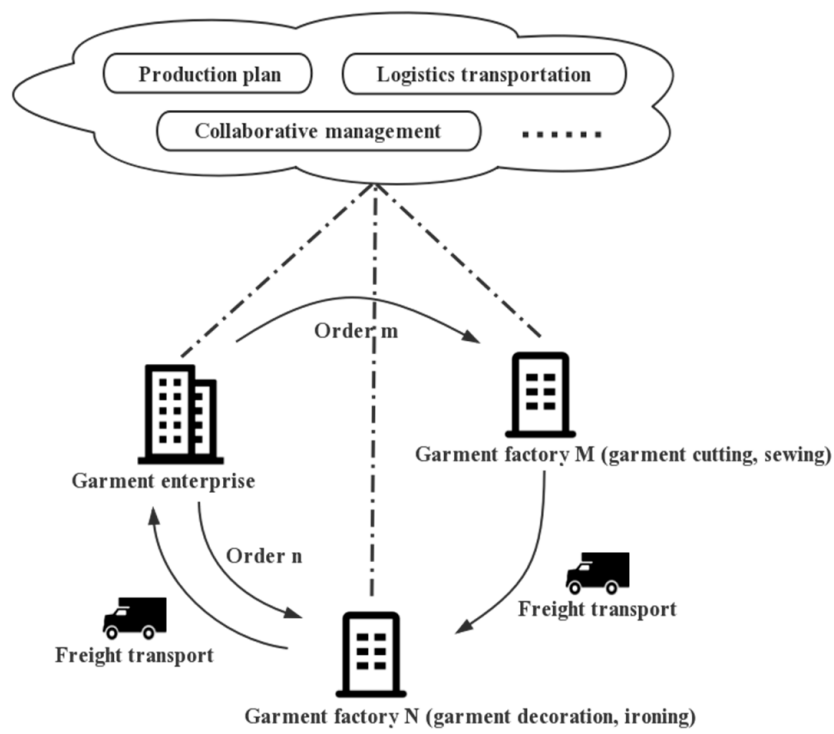

Figure 8. Schematic diagram of a virtual joint factory formed by a garment enterprise and outsourcing processing factories.

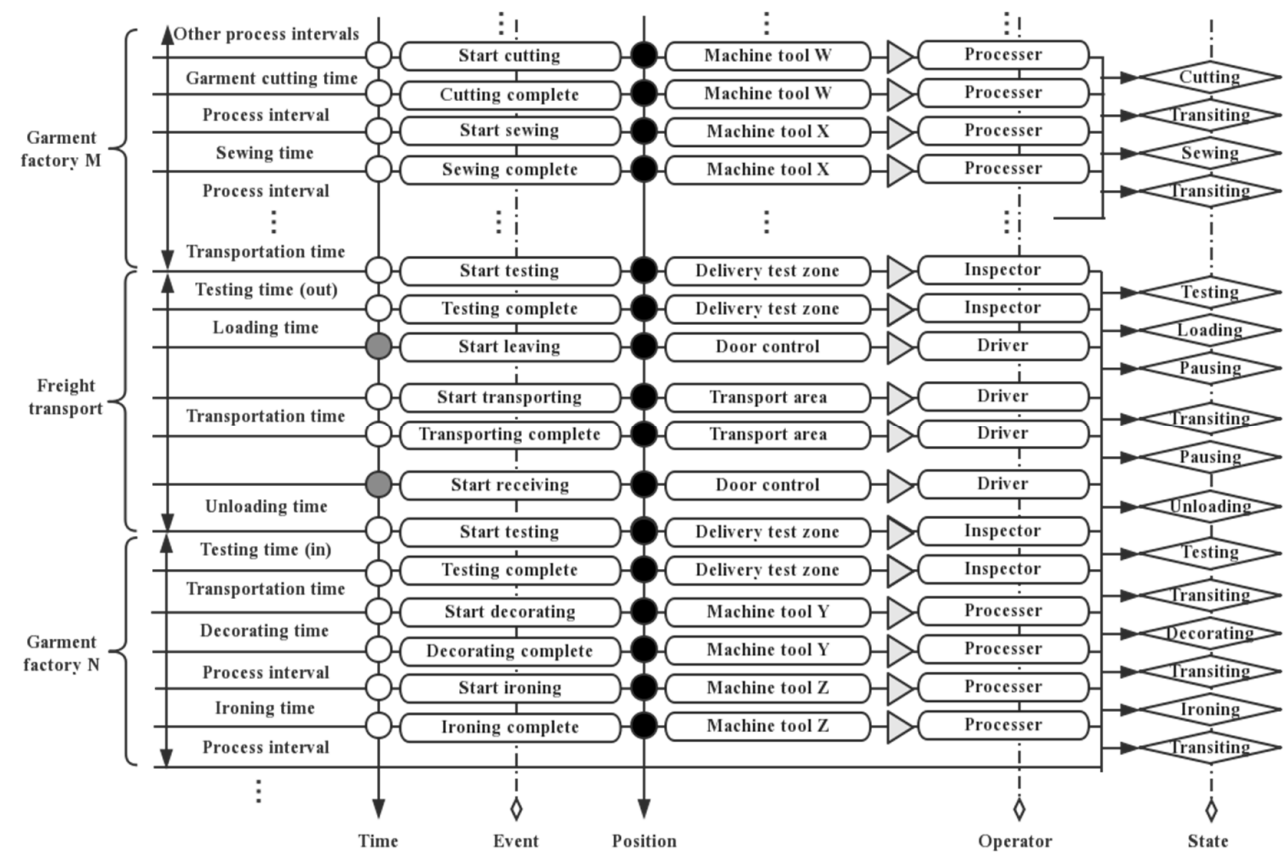

Figure 9. Process flow monitoring diagram based on RFID configuration for garment outsourcing processing. 


\section{Discussion}

From the tracking and monitoring technology in industrial production and manufacturing processes that has been realized, data collection was realized through multiple methods according to the collection principle of man-machine combination. The data collection method was not uniform, and the communication protocol standard of the underlying device was also inconsistent [19]. In terms of the application of the MES system, its main function is information management and "upload release". The ability of real-time monitoring in the production and manufacturing process of logistics distribution and the whole life cycle of products is still weak [20], and there is also a gap between system information management and real-time information updates.

Compared with the tracking and monitoring technology in the current mainstream manufacturing process, the RFID based cloud MES system proposed in this paper is a combination of RFID, cloud storage and big data technology and the community mode. Its advantages are mainly reflected in the following three aspects:

(1) The data collection method based on RFID technology was convenient and fast, reduced manpower, saved time, improved data accuracy, and helped to automate the manufacturing process. At the same time, in view of the different enterprise production which requires corresponding RFID tracking configuration, it helped to achieve refinement of the management of the whole manufacturing process.

(2) Under the control of the cloud MES system, the introduction of key technologies based on cloud storage and big data processing, and data mining for RFID real-time data streams, the proposed system can find key data, and provide dynamic information for real-time decision-making to solve production problems and help to make the manufacturing process intelligent.

(3) The combination of the community model and the cloud MES system enables collaborative interactions, collaborative production and coordinated management and control among the cooperative enterprises, which contributes to the synergy of the manufacturing process.

\section{Conclusions and Future Work}

This study proposes a RFID-based manufacturing process of cloud MES. First of all, the framework of the manufacturing process of cloud MES system centered on machine tools is constructed. Secondly, the RFID configuration and cloud processing of the manufacturing process are analyzed in combination with the framework, including the process division of the production process, the RFID tracking configuration based on process division, and the cloud MES processing based on RFID configuration. Thirdly, a brief discussion of other key technologies involved in implementing the framework is included.

Through two different types of case analyses (photovoltaic slice production and garment outsourcing processing), it is verified that the RFID-based manufacturing process of the cloud MES can effectively realize tracking and monitoring of key nodes, which is beneficial to real-time dynamic acquisition of process information for production decisions. Providing the basis, saving on costs, and improving efficiency have broad application prospects. However, this study focuses on the analysis of the tracking configuration and monitoring model of RFID in the production process. The RFID collection network and the community manufacturing mode have not been discussed in detail. The next step will be to focus on cloud MES based process tracking and monitoring of social manufacturing.

Author Contributions: Methodology, C.W.; Resources, X.C.; Writing-Review \& Editing, A.A.S.; Supervision, Z.Z. The above authors' contribution in manuscript writing are comparable.

Funding: This research received no external funding.

Conflicts of Interest: The authors declare no conflicts of interest. 


\section{References}

1. MESA International. MES Explained: A High Level Vision for Executives. Available online: https://services. mesa.org/resourcelibrary/showresource/334444c5-388f-4360-beb4-3c86dc0f4de4 (accessed on 26 October 2018).

2. Integratable MES: The Challenge and the Opportunity. Available online: http://www.oalib.com/references/ 18332453 (accessed on 26 October 2018).

3. Cao, J. Studies on Key Technologies of Manufacturing Execution System Oriented to the Agily Manufacturing. Ph.D. Thesis, Nanjing University of Aeronautics and Astronauties, Nanjing, China, 2002. (In Chinese)

4. Wang, C. Research on the Key Technologies of Human-Centered Manufacturing Execution System in Networked Manufacturing. Ph.D. Thesis, Hefei University of Technology, Hefei, China, 2005. (In Chinese)

5. Tang, T.; Lin, T.; Jie, W.; Ming, C. Full realization of digitalization is the only way to intelligent manufacturing. China Mech. Eng. 2018, 29, 366-377.

6. Wang, Y. Optimization Technologies of Manufacturing Execution System in Cloudy Manufacturing and Applications in Machine Production Enterprise. Ph.D. Thesis, Zhejiang University, Hangzhou, China, 2011. (In Chinese)

7. Helo, P.; Suorsa, M.; Hao, Y.; Anussornnitisarn, P. Toward a cloud-based manufacturing execution system for distributed manufacturing. Comput. Ind. 2014, 65, 646-656. [CrossRef]

8. Jianchao, Z.; Chong, Z.; Fan, Z. Discussion on the construction of cloud MES for industrial parks. Manuf. Autom. 2018, 40, 94-97.

9. MESA International. MES Software-Evaluation/Selection [EB/OL]. August 2007. Available online: https:// services.mesa.org/resourcelibrary / showresource/e1734dd2-2f28-432b-a646-3f75384770cb.2007-8 (accessed on 26 October 2018).

10. Zhou, S.; Ling, W.; Peng, Z. An RFID-based remote monitoring system for enterprise internal production management. Int. J. Adv. Manuf. Technol. 2007, 33, 837-844. [CrossRef]

11. Fu, Y. RFID Based Key Enabling Technologies for He Running of Service-Oriented Manufacturing Execution Systems in Shop Floor. Ph.D. Thesis, Xi'an Jiaotong University, Xi'an, China, 2012.

12. Guo, Z.; Ngai, E.; Yang, C.; Liang, X. An RFID-based intelligent decision support system architecture for production monitoring and scheduling in a distributed manufacturing environment. Int. J. Prod. Econ. 2015, 159, 16-28. [CrossRef]

13. Jiang, P.; Sun, P.; Kai, D.; Chuang, W. Radio Frequency Identification-based Graphical Formalized Deduction Method for Process Tracking and Its Industrial Applications. J. Mech. Eng. 2015, 51, 9-17. [CrossRef]

14. Ding, K.; Jiang, P.; Su, S. RFID-enabled social manufacturing system for inter-enterprise monitoring and dispatching of integrated production and transportation tasks. Robot. Comput. Integr. Manuf. 2018, 49, 120-133. [CrossRef]

15. Mccarthy, I.; Anagnostou, A. The impact of outsourcing on the transaction costs and boundaries of manufacturing. Int. J. Prod. Econ. 2004, 88, 61-71. [CrossRef]

16. Yin, S.; Yin, C.; Liu, F.; Li, X.B. Outsourcing resources integration service mode and semantic description in cloud manufacturing environment. Comput. Integr. Manuf. Syst. 2011, 17, 525-532.

17. Cao, W.; Jiang, P.; Jiang, K.; Lu, P. Radio frequency identification-based real-time data collecting and visual monitoring for discrete manufacturing workshop. Comput. Integr. Manuf. Syst. 2017, 23, 273-284.

18. Jiang, P.; Ding, K.; Leng, J. Social manufacturing: drivers, research status, and trends. Ind. Eng. J. 2016, 19, $1-9$.

19. Kang, L.; Kaiyu, J.; Ji, Z. Summary of the Data Acquisition Technology for MES. Die Mould Manuf. 2018, 18, 66-70.

20. Wenhu, L. Design and Realization of Manufacturing Execution System Based on MicroService Architecture. Master's Thesis, Zhejiang University, Hangzhou, China, 2018.

(C) 2018 by the authors. Licensee MDPI, Basel, Switzerland. This article is an open access article distributed under the terms and conditions of the Creative Commons Attribution (CC BY) license (http://creativecommons.org/licenses/by/4.0/). 